\title{
The rest of the story: Long-term, patient-reported outcomes in cardiac surgery
}

\author{
William Z. Chancellor, MD, and Irving L. Kron, MD
}

\author{
From the Division of Thoracic and Cardiovascular Surgery, Department of Surgery, University of Virginia, Char- \\ lottesville, Va. \\ Disclosures: Authors have nothing to disclose with regard to commercial support. \\ Received for publication May 21, 2018; revisions received May 21, 2018; accepted for publication May 23, 2018; \\ available ahead of print July 11, 2018 \\ Address for reprints: Irving L. Kron, MD, Division of Thoracic and Cardiovascular Surgery, Department of Sur- \\ gery, University of Virginia, PO Box 800679, Charlottesville, VA 22908 (E-mail: ilk@ virginia.edu). \\ J Thorac Cardiovasc Surg 2018;156:2191 \\ $0022-5223 / \$ 36.00$ \\ Copyright (c) 2018 by The American Association for Thoracic Surgery \\ https://doi.org/10.1016/j.jtcvs.2018.05.093
}

Despite the volume and quality of research to support surgical management of cardiac disease, there are relatively few studies that quantify its long-term, functional benefits. In this issue of the Journal, Gjeilo and colleagues ${ }^{1}$ report the 10-year results of a prospective, population-based study assessing patient-reported functional status and health-related quality of life after cardiac surgery. ${ }^{1}$ Unsurprisingly, Gjeilo and colleagues ${ }^{1}$ found that patients are eager to report dramatic improvements in their health once they have returned home.

Gjeilo and colleagues ${ }^{1}$ are to be commended on a thoughtfully designed and well-executed study of 534 consecutive cardiac surgery patients that included preoperative self-reported New York Heart Association functional classification and validated health-related quality of life surveys. These questionnaires were repeated at 6 months and then at 1, 5, and 10 years, with an impressive 78\% 10year follow-up for eligible respondents. Gjeilo and colleagues ${ }^{1}$ achieved $68 \%$ survival in all comers at 10 years, and survival of younger patients was on par with that of the general population. Overall, patients reported improvement in heart failure symptoms and health-related quality of life by 6 months, which was largely sustained long term.

This work is representative of a much-needed shift toward patient-centered outcomes in cardiac surgery. Our specialty has relied on 30-day mortality - an insufficient marker of success - for far too long. Their excellent longterm survival and reported improvement in quality of life are welcomed in an era that prioritizes value in health care, and I am confident they are representative of cardiac surgery outcomes around the world. This kind of highquality data will allow for more accurate, personalized preoperative counseling and risk stratification. In addition, these results should serve as a benchmark for emerging technologies, such as minimal access surgery and transcatheter cardiac interventions. of life.

\section{References}

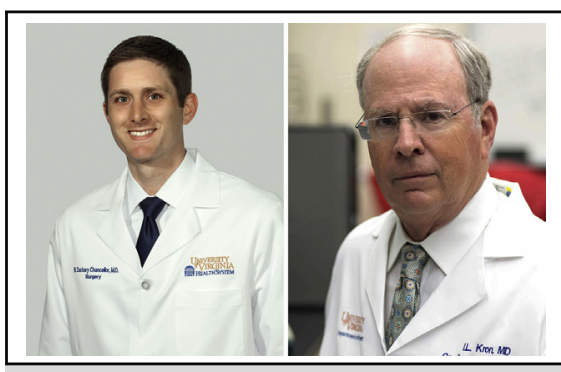

William Z. Chancellor, MD (left), and Irving L. Kron, $\mathrm{MD}$ (right)

\section{Central Message}

Cardiac surgery is associated with sustained improvements in self-reported functional outcomes and health-related quality of life.

See Article page 2183.

Gjeilo and colleagues ${ }^{1}$ showed that, despite presenting with complex cardiovascular disease and undergoing a variety of operations, patients report dramatically improved function just 6 months after sternotomy, which is similar to results recently published for isolated coronary revascularization. $^{2,3}$ However, in such a heterogenous cohort, some patients likely benefited more than others, and a few undoubtedly declined. Although the authors ${ }^{1}$ identified older patients as more likely to report worse general health with time, they missed an excellent opportunity to explore further risk factors for unfavorable outcomes. Future studies would do well to include additional subanalyses to determine modifiable and nonmodifiable factors that are associated with sustained improvement in quality

1. Gjeilo KH, Stenseth R, Wahba A, Lydersen S, Klepstad P. Long-term healthrelated quality of life and survival after cardiac surgery: a prospective study. $J$ Thorac Cardiovasc Surg. 2018;156:2183-90.e2.

2. Abdallah MS, Wang K, Magnuson EA, Osnabrugge RL, Kappetein AP, Morice MC, et al. Quality of life after surgery or DES in patients with 3-vessel or left main disease. J Am Coll Cardiol. 2017;69:2039-50.

3. Stenvall H, Tierala I, Räsänen P, Laine M, Sintonen H, Roine RP. Long-term clinical outcomes, health-related quality of life, and costs in different treatment modalities of stable coronary artery disease. Eur Heart J Qual Care Clin Outcomes. 2017;3:74-82. 